\title{
Interactive Effects of Temperature and Leaf Wetness Duration on Sporangia Germination and Infection of Cucurbit Hosts by Pseudoperonospora cubensis
}

\author{
K. N. Neufeld and P. S. Ojiambo, Department of Plant Pathology, North Carolina State University, Raleigh 27695
}

\begin{abstract}
Neufeld, K. N., and Ojiambo, P. S. 2012. Interactive effects of temperature and leaf wetness duration on sporangia germination and infection of cucurbit hosts by Pseudoperonospora cubensis. Plant Dis. 96:345-353.

Outbreaks of cucurbit downy mildew caused by Pseudoperonospora cubensis are dependent on the weather but effects of temperature and leaf wetness duration on infection have not been studied for different cucurbits. To determine the effects of these two weather variables on sporangia germination and infection of cucurbit host types by $P$. cubensis, three host types; cucumber ('Straight 8'), cantaloupe ('Kermit'), and acorn squash ('Table Queen'), were inoculated and exposed to leaf wetness durations of 2 to $24 \mathrm{~h}$ at six constant temperatures ranging from 5 to $30^{\circ} \mathrm{C}$ in growth-chamber experiments. Sporangia germination was assessed after each wetness period, and leaf area infected was assessed 5 and 7 days after inoculation. Germination of sporangia was highest on cantaloupe (16.5 to $85.7 \%$ ) and lowest on squash (10.7 to $68.9 \%$ ), while disease severity was highest and lowest on cucumber and cantaloupe, respectively. Host type, temperature, wetness duration and their interactions significantly $(P<$ 0.0001 ) affected germination and disease severity. Germination and disease data for each host type were separately fitted to a modified

form of a Weibull function that characterizes a unimodal response and monotonic increase of germination or infection with temperature and wetness duration, respectively. The effect of host type on germination and infection was characterized primarily by differences in the upper limit parameter in response to temperature. Differences among host types based on other parameters were either small or inconsistent. Temperature and wetness duration that supported a given level of germination or infection varied among host types. At $20^{\circ} \mathrm{C}, 15 \%$ leaf area infected was expected following 2,4 , and $8 \mathrm{~h}$ of wetness for cucumber, squash, and cantaloupe, respectively. When temperature was increased to $25^{\circ} \mathrm{C}, 15 \%$ disease severity was expected following 3,7 , and $15 \mathrm{~h}$ of wetness for cucumber, squash, and cantaloupe, respectively. Risk charts were constructed to estimate the potential risk of infection of cucurbit host types by $P$. cubensis based on prevailing or forecasted temperature and leaf wetness duration. These results will improve the timing and application of the initial fungicide spray for the control of cucurbit downy mildew.
\end{abstract}

Among the diseases that affect cucurbitaceous crops, downy mildew caused by the oomycete Pseudoperonospora cubensis is economically the most damaging (8). Several cucurbit host types are infected by $P$. cubensis, of which cucumber (Cucumis sativus); squash, pumpkin, and zucchini (Cucurbita pepo); watermelon (Citrullus lanatus); and cantaloupe and muskmelon (Cucumis melo) are economically the most important crop plants (9). The disease has a worldwide distribution and occurs wherever cucurbits are cultivated in temperate and tropical areas and in the semiarid areas in the Middle East. In these production regions, the disease is especially damaging in areas with warm and humid conditions which are conducive for disease development (22). In the United States, these favorable environmental conditions commonly occur in the eastern half of the country, where epidemics of the disease occur annually. Since 2007, cucurbit downy mildew now occurs annually in California (12).

The degree of infection of cucurbits by $P$. cubensis is greatly influenced by temperature and leaf wetness. Leaf wetness allows for infection to occur, while temperature determines the extent of disease development $(1,3)$. Thus, disease development is minimal in the absence of leaf wetness regardless of the prevailing temperature (14). The minimum duration of leaf wetness required for infection is $2 \mathrm{~h}$ (3) and the optimum temperature for infection is between 15 and $20^{\circ} \mathrm{C}$ (4). The interactive effects of temperature and leaf wetness duration also influence sporangia germination (1) and the extent and degree of disease severity $(1,3)$. Quantitative models based on modified forms of the Weibull function were recently developed to describe the combined effects of temperature

Corresponding author: P. S. Ojiambo, E-mail: peter_ojiambo@ncsu.edu

Accepted for publication 28 September 2011.

http://dx.doi.org/10.1094/PDIS-07-11-0560

(C) 2012 The American Phytopathological Society and leaf wetness duration (1). Using cantaloupe as the cucurbit host type, the models estimated 15 to 17 and 19 to $22^{\circ} \mathrm{C}$ as the optimum temperature range for germination and infection, respectively, with little germination or infection at 5 or $30^{\circ} \mathrm{C}$ (1). For wetness periods of 4 to $8 \mathrm{~h}$, a distinct optimum for infection was observed at $20^{\circ} \mathrm{C}$; however, broader optimum curves resulted from wetness periods $>8 \mathrm{~h}$. Based on these models, risk threshold charts were constructed for estimating the potential risk for infection based on observed or forecasted temperature and leaf wetness duration (1). Studies on the influence of weather variables can generate useful information needed to improve management of plant diseases. For example, temperature and wetness duration are used together with information on known inoculum sources to forecast the risk of cucurbit downy mildew outbreak in the United States (12).

Currently, there are no commercially available resistant cucurbit cultivars, and control of cucurbit downy mildew relies heavily on the use fungicides such as fluopicolide (Presidio), cyazofamid (Ranman), and propamocarb hydrochloride (Previcur Flex). In the absence of any resistance management strategies, heavy use of these fungicides can result in $P$. cubensis developing resistance to these chemistries. Field observations and empirical studies $(13,23)$ indicate that cucurbits respond differentially to infection by $P$. cubensis. For example, cucumber is generally more susceptible to $P$. cubensis than other cucurbitaceous host crops $(13,23)$. Because temperature and wetness duration are the key variables that influence sporangia germination and infection by $P$. cubensis, it is logical to expect that there will be a corresponding differential response of cucurbit host types to temperature and leaf wetness duration, either alone or in combination. However, the cucurbit downy mildew forecasting system (12) issues forecasts for the initial infection based on the assumption that infection parameters for different cucurbits respond similarly to temperature and wetness duration. In a study on early leaf spot of peanut, Wu et al. (26) observed that cultivars varied in their response to wetness and temperature and proposed improvement in the performance and 
efficiency of an early leaf spot advisory program through modification of wetness duration thresholds for cultivars that differ in their reaction to the disease. The differential response of cucurbit host types to temperature and leaf wetness has not yet been determined for $P$. cubensis and such information, when developed, could be used to improve the performance and efficiency of the cucurbit downy mildew forecasting system. Thus, this study was carried out with the following objectives: (i) quantify the temperature and leaf wetness duration for sporangia germination and infection of cucurbit host types by $P$. cubensis and (ii) develop risk charts to predict infection of cucurbit host types by $P$. cubensis for a wide range of temperature and leaf wetness duration.

\section{Materials and Methods}

Cucurbit host types and plant growth conditions. Three cucurbit host types were used in this study: cucumber ('Straight 8'), cantaloupe ('Kermit'), and acorn squash ('Table Queen'). Cucumber and squash seed were directly seeded and seedlings grown in circular 8-cm Styrofoam cups (one plant/cup) containing vermiculite. However, cantaloupe seed were first germinated in petri plates incubated in a growth chamber with no light at $30^{\circ} \mathrm{C}$ for 2 days, and then the seedlings were transplanted into circular $8.0-\mathrm{cm}$ Styrofoam cups (one plant/cup) containing vermiculite. All plants were thereafter maintained in a greenhouse with a natural light cycle of $12 \mathrm{~h} /$ day and $12 \mathrm{~h} /$ night and temperature regime of 32 and $26^{\circ} \mathrm{C}$ day and night, respectively. Plants were watered daily with deionized water in the morning and half-strength Hoagland's solution (6) in the afternoon during the experimental period.

Pathogen isolate and inoculation of plants. An isolate of $P$. cubensis (JCNC-09), which was isolated from Straight 8 cucumber in Johnston County, NC in 2009, was used for inoculation of test plants. This isolate (previously maintained on leaf tissue in a $-80^{\circ} \mathrm{C}$ freezer) is capable of infecting different cucurbit host types and was used to produce adequate amounts of sporangia suspension for plant inoculation, as described previously (7). At the twotrue-leaf stage (approximately 21 days old), plants were randomly selected and first preconditioned in growth chambers at 5, 10, 15, 20,25 , and $30^{\circ} \mathrm{C}$ overnight. The first and second true leaves were then inoculated on the abaxial and adaxial sides of the leaves with a spore suspension containing $1 \times 10^{4}$ sporangia/ml in deionized water until run-off using a Preval sprayer (Complete Unit 267; Precision Valve Corporation, Yonkers, NY). Following inoculation, plants were immediately covered with plastic bags to ensure that the required leaf wetness duration persisted during the test periods. Inoculated plants were then incubated in growth chambers with 24 $\mathrm{h}$ of darkness at the above six temperatures to optimize infection of plants (7).

Leaf wetness durations evaluated in this study were $2,4,8,12$, and $24 \mathrm{~h}$. To evaluate sporangia germination for each wetness period, inoculated plants incubated at each of the six temperatures were removed from growth chambers after a given leaf wetness duration. Leaf disks measuring $10 \mathrm{~mm}$ were removed from the first and second leaves using a cork borer and immediately placed in microcentrifuge tubes containing $12 \% \mathrm{CuSO}_{4}$ solution to inhibit germination of sporangia (2). The contents in the microcentrifuge tubes were vortexed for $5 \mathrm{~s}$, and $25 \mu \mathrm{l}$ of the solution was pipetted onto a slide and covered with a cover slip to examine sporangia for germination using a microscope. Sporangia of $P$. cubensis germinate indirectly by cytoplasmic cleavage to release zoospores and, therefore, a sporangium was considered germinated when the cytoplasmic contents were emptied. In total, 50 sporangia were examined for each temperature and leaf wetness combination.

The effects of temperature and leaf wetness duration on infection of cucurbit host types by $P$. cubensis were evaluated in two steps. For each of the six temperature regimes, inoculated plants were first exposed to the five different leaf wetness durations by removing three plants from each growth chamber after $2,4,8,12$, and $24 \mathrm{~h}$ of leaf wetness. Plants were then dried with forced air for about $10 \mathrm{~min}$ and returned to their respective growth chambers, where they were exposed to ambient humidity in the chamber for
$24 \mathrm{~h}$. In the second stage, all plants were removed from the growth chamber and exposed to standard incubation conditions (21 and $18^{\circ} \mathrm{C}$ day and night temperatures and 12 and $12 \mathrm{~h}$ darkness and light regimes, respectively; and 75 to $90 \%$ relative humidity) in an incubator (Model I-36VL; Percival Scientific Inc., Perry, IA). Plants were evaluated for disease severity (two leaves per plant) at 5 and 7 days after inoculation (DAI) by visually assessing the percentage of leaf area affected with chlorotic and necrotic symptoms. The two disease assessment periods represent the range of the latent period of $P$. cubensis (22). Both sporangia germination and infection experiments were conducted twice.

Experimental design and data analysis. Treatments were laid out in a split-split-plot design with temperature as the whole-plot treatment, host type as the split-plot treatment, and leaf wetness duration as the split-split-plot treatment. Each combination of temperature and leaf wetness duration comprised two replications of two and three plants for germination and disease severity, respectively, with two inoculated leaves per plant.

A preliminary analysis of variance indicated no significant differences between the two experiments conducted for the germination and infection data. Thus, all subsequent analyses were performed on data averaged over the two experiments. Analysis of germination and infection data was conducted in two steps. First, the effects of temperature $(t)$, host type $(s)$, and leaf wetness duration $(w)$ on sporangia germination and disease severity were compared by analysis of variance using PROC GLM of SAS (version 9.2; SAS Institute, Cary, NC).

In the second set of analysis, the response of individual host types to the combined effects of temperature and leaf wetness were modeled by fitting germination and infection data to the following nonlinear model (1):

$f(w, t)=f(t) \times\left(1-\exp \left\{-[B \times w]^{D}\right\}\right)$

where $f(t)$, which is the asymptote parameter, is defined as:

$\left.f(t)=E^{\prime}\{\exp [(t-F) G /(H+1)]\} /\{1+\exp (t-F) G]\right\}$

and where $E^{\prime}$ is defined as:

$E^{\prime}=E[(H+1) / H] H^{1 /(H+1)}$

This model is a modified form of a Weibull function (24) and was recently developed and validated to describe the response of sporangia germination and infection by $P$. cubensis to combined effects of temperature and leaf wetness using cantaloupe as the model system (1). In the above equations, italicized lowercase letters represent independent variables, while italicized uppercase letters represent parameters. Briefly, the asymptote parameter, $f(t)$, characterizes the upper limit of the response variable as $w$ is extended indefinitely. Parameter $B$ refers to the intrinsic rate of increase of the response variable with respect to $w$, while parameter $D$ is the intrinsic rate of acceleration. The parameter $E$ characterizes the scale of the response to $t$. The parameters $F$ and $G$ characterize the rate of change of the response variable with respect to optimum temperature and temperature, respectively. The asymmetry in the response to $t$ is characterized by parameter $H$. Sporangia germination and infection data averaged over replications were fitted to the nonlinear model using the PROC NLIN in SAS. Goodness-of-fit of the model was evaluated based on the significance of parameter estimates, magnitude of asymptotic standard errors, and simple correlation between observed and predicted germination or infection values.

Risk chart models. Curves derived from the final model parameter estimates for the range of temperature and leaf wetness duration required to attain thresholds values of disease severity evaluated at 7 DAI were used to generate isopaths for predicting risk of downy mildew development for each cucurbit host type. This was achieved by integrating the asymptote (equation 1.1), with the estimated values for parameters $B$ and $D$ to generate predicted disease severity as a function of $t$ and $w$. Based on the level of disease severity, risk categories were defined as light, moderate, 
and severe for 0 to 10,10 to 20 , and $>20 \%$ leaf area infected, respectively. These disease severity classes resulted in combinations of temperature and leaf wetness duration that were distinctly different among the three risk categories.

\section{Results}

Sporangia germination and disease severity. Sporangia germination averaged across all temperatures and leaf wetness combinations was highest for the cantaloupe and lowest for squash (Table 1) in both experiments, while sporangia germination was intermediate for cucumber. Disease severity evaluated at 5 and 7 DAI and averaged across all combinations of temperature and leaf wetness duration was highest for cucumber and lowest for cantaloupe in both experiments, while disease severity for squash was intermediate (Table 1). The extent of differences between host types was dependent on the response variable. For example, sporangia germination on cucumber and squash was 16 and 32\%, respectively, lower than that for cantaloupe in both experiments. For disease severity, however, differences between host types were greater for disease severity evaluated at 5 DAI than for disease severity evaluated at 7 DAI. In experiment 1, for example, squash had $25 \%$ less leaf area infected at 5 DAI than cucumber whereas, at 7 DAI, cantaloupe had 5\% less leaf area infected than cucumber.

No significant $(P>0.05)$ differences in germination and disease severity were observed between the first and second experiments. In the analysis of variance, host type, temperature, and leaf wetness duration significantly $(P<0.0001)$ affected germination and disease severity at 5 and 7 DAI. Further, both sporangia germination and disease severity were also significantly $(P<0.001)$ affected by the interactions between host type, temperature, and leaf wetness duration (Table 2). Variation in temperature response within experimental runs (split-plot error) was not significant $(P>0.05)$ for disease severity at 5 and 7 DAI but was marginally significant $(P=0.045)$ for sporangia germination. Similarly, variation in temperature response of germination and disease severity among host types within experimental runs was not significant $(P>0.05)$ except for disease severity evaluated at 7 DAI (Table 2).

The range of temperature and wetness duration that supported high levels of germination varied among host types. For example, for cantaloupe, the highest proportion of germinated sporangia ( $\geq 60 \%$ ) was attained at $t=10$ to $30^{\circ} \mathrm{C}$ for $w \geq 8 \mathrm{~h}$ whereas, for squash, the same level of germination was attained at $t=15$ to $20^{\circ} \mathrm{C}$ for $w \geq 12 \mathrm{~h}$ (Fig. $1 \mathrm{~A}$ and E). The corresponding level of germination for cucumber was attained for $t=10$ to $25^{\circ} \mathrm{C}$ and $w \geq$ $8 \mathrm{~h}$ (Fig. 1C). For all host types, the lowest levels of germination $(\leq 20 \%)$ were observed at $t=5^{\circ} \mathrm{C}$ and $w=2$ or $4 \mathrm{~h}$ except for squash, where this lowest level of germination was also observed for $t=30^{\circ} \mathrm{C}$ and $w \leq 4 \mathrm{~h}$. The optimum temperature for germination was $19.9,19.3$, and $19.9^{\circ} \mathrm{C}$ for cantaloupe, cucumber, and squash, respectively.

For all temperatures evaluated, an increase in wetness resulted in an increase in infection in all the host types except at $5^{\circ} \mathrm{C}$, where

Table 1. Sporangia germination and severity of cucurbit downy mildew on three cucurbit host types inoculated with Pseudoperonospora cubensis in two growth-chamber experiments

\begin{tabular}{|c|c|c|c|c|c|c|}
\hline \multirow[b]{2}{*}{ Run, host type ${ }^{c}$} & \multicolumn{2}{|c|}{ Sporangia germination $(\%)^{\mathbf{a}}$} & \multicolumn{2}{|c|}{ Disease severity $(\%)(5 \text { DAI })^{b}$} & \multicolumn{2}{|c|}{ Disease severity (\%) (7 DAI) } \\
\hline & Mean \pm SE & $n$ & Mean \pm SE & $n$ & Mean \pm SE & $n$ \\
\hline \multicolumn{7}{|l|}{1} \\
\hline Cantaloupe & $53.3 \pm 0.028$ & 60 & $8.2 \pm 0.005$ & 112 & $13.4 \pm 0.008$ & 127 \\
\hline Cucumber & $44.5 \pm 0.025$ & 60 & $18.3 \pm 0.009$ & 150 & $24.1 \pm 0.011$ & 137 \\
\hline Acorn squash & $36.1 \pm 0.022$ & 60 & $13.6 \pm 0.008$ & 120 & $22.7 \pm 0.015$ & 108 \\
\hline Mean & $44.6 \pm 0.016$ & 180 & $13.4 \pm 0.005$ & 382 & $20.1 \pm 0.009$ & 372 \\
\hline \multicolumn{7}{|l|}{2} \\
\hline Cantaloupe & $53.0 \pm 0.029$ & 60 & $9.9 \pm 0.005$ & 140 & $14.0 \pm 0.005$ & 155 \\
\hline Cucumber & $44.3 \pm 0.027$ & 60 & $16.6 \pm 0.007$ & 164 & $23.4 \pm 0.009$ & 147 \\
\hline Acorn squash & $36.0 \pm 0.021$ & 60 & $12.1 \pm 0.006$ & 117 & $17.3 \pm 0.009$ & 129 \\
\hline Mean & $44.4 \pm 0.015$ & 180 & $12.9 \pm 0.004$ & 421 & $18.2 \pm 0.005$ & 431 \\
\hline
\end{tabular}

${ }^{\text {a }}$ Sporangia germination values are means over six temperatures, five durations of leaf wetness, two plants, and two inoculated leaves per plant; SE = standard error and $n=$ sample size.

${ }^{\mathrm{b}}$ Disease severity values are means over six temperatures, five durations of leaf wetness, three plants, and two inoculated leaves per plant, assessed 5 and 7 days after inoculation (DAI); $n=$ sample size.

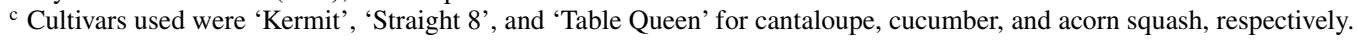

Table 2. Analysis of variance for the effects of temperature $(t)$, cucurbit host type $(s)$, and leaf wetness duration $(w)$ on germination of sporangia of Pseudoperonospora cubensis and severity of cucurbit downy mildew ${ }^{\mathrm{a}}$

\begin{tabular}{|c|c|c|c|c|c|c|c|c|c|}
\hline \multirow[b]{2}{*}{ Source } & \multicolumn{3}{|c|}{ Sporangia germination (proportion) } & \multicolumn{3}{|c|}{ Disease severity (5 DAI) ${ }^{b}$} & \multicolumn{3}{|c|}{ Disease severity (7 DAI) ${ }^{b}$} \\
\hline & df & SS & $P>F$ & df & SS & $P>F$ & df & SS & $P>F$ \\
\hline Replication $(r)$ & 3 & 0.00 & 0.7965 & 5 & 0.01 & 0.4450 & 5 & 0.01 & 0.0101 \\
\hline$t$ & 5 & 3.57 & 0.0001 & 5 & 1.22 & 0.0001 & 5 & 2.41 & 0.0001 \\
\hline$t(r)$ - error a & 15 & 0.01 & 0.0364 & 25 & 0.03 & 0.4266 & 25 & 0.06 & 0.0449 \\
\hline Whole-plot total & 23 & $\ldots$ & $\ldots$ & 35 & $\ldots$ & $\ldots$ & 35 & $\ldots$ & $\ldots$ \\
\hline$s$ & 2 & 1.75 & 0.0001 & 2 & 0.49 & 0.0001 & 2 & 0.87 & 0.0001 \\
\hline$s \times t$ & 10 & 0.27 & 0.0001 & 10 & 0.07 & 0.0001 & 10 & 0.30 & 0.0001 \\
\hline$s \times t(r)-$ error b & 36 & 0.01 & 0.1558 & 60 & 0.07 & 0.4138 & 60 & 0.15 & 0.1016 \\
\hline Split-plot total & 48 & $\ldots$ & $\ldots$ & 72 & $\ldots$ & $\ldots$ & 72 & $\ldots$ & $\ldots$ \\
\hline$w$ & 4 & 10.17 & 0.0001 & 4 & 0.74 & 0.0001 & 4 & 1.21 & 0.0001 \\
\hline$w \times t$ & 20 & 0.08 & 0.0001 & 20 & 0.10 & 0.0001 & 20 & 0.33 & 0.0001 \\
\hline$w \times s$ & 8 & 0.48 & 0.0001 & 8 & 0.03 & 0.0002 & 8 & 0.05 & 0.0002 \\
\hline$w \times s \times t$ & 40 & 0.14 & 0.0001 & 40 & 0.12 & 0.0001 & 40 & 0.27 & 0.0001 \\
\hline$w \times s \times t(r)-$ error $\mathrm{c}$ & 216 & 0.08 & $\ldots$ & 317 & 0.34 & $\ldots$ & 318 & 0.47 & $\ldots$ \\
\hline Split-split-plot total & 288 & $\ldots$ & $\ldots$ & 389 & $\ldots$ & $\ldots$ & 390 & $\ldots$ & $\ldots$ \\
\hline Total & 359 & $\ldots$ & $\ldots$ & $496^{c}$ & $\ldots$ & $\ldots$ & $497^{c}$ & $\ldots$ & $\ldots$ \\
\hline
\end{tabular}

a Analysis of variance was conducted on mean values for two plants, with two inoculated leaves per plant.

${ }^{\mathrm{b}}$ Disease severity (leaf area infected, expressed as a proportion) was determined 5 and 7 days after inoculation (DAI).

c Overall, 43 and 42 observations were missing when disease severity was assessed 5 and 7 DAI, respectively, due to loss of plants. 
the increase infection was minimal. The optimum range of temperature and wetness duration for disease severity varied among host types. At $5 \mathrm{DAI}$, disease severity $>15 \%$ was observed at $t=15$ to $25^{\circ} \mathrm{C}$ for $w \geq 12 \mathrm{~h}$ for cantaloupe, $t=10$ to $30^{\circ} \mathrm{C} w \geq 4 \mathrm{~h}$ for cucumber, and $t=20$ to $25^{\circ} \mathrm{C}$ for $w \geq 4 \mathrm{~h}$ for squash (Fig. 2). A similar trend was observed for severity evaluated at 7 DAI, except that the optimum range for infection was much broader for $w$ than that observed at 5 DAI for all the host types (Fig. 3). For example, at $t=15$ to $25^{\circ} \mathrm{C},>15 \%$ leaf area infected on cantaloupe was observed for $w \geq 4$ h at 7 DAI compared with $w \geq 12 \mathrm{~h}$ at 5 DAI. The optimum temperature for infection at 7 DAI was 20.5, 20.1, and $17.6^{\circ} \mathrm{C}$ for cantaloupe, cucumber, and squash, respectively.

Model evaluation and parameter estimates. Combined effects of $t$ and $w$ on germination and infection of cucurbit host types by $P$. cubensis were well described by the model. For each host type, germination and disease severity increased sigmoidally when $w$ was increased, whereas the response of the variables to temperature was unimodal, with highest and lowest values being around the middle and the extreme range of temperatures, respectively. Plots of observed germination (Fig. 1) and infection (Figs. 2 and 3) were similar to those of predicted values for all host types. The correlation coefficients $(r)$ between predicted and observed germination were $0.962,0.951$, and 0.973 for cantaloupe, cucumber, and squash, respectively. The $r$ values for disease severity at 5 DAI were $0.919,0.895$, and 0.912 , for cantaloupe, cucumber, and squash, respectively, and the corresponding values for disease severity at 7 DAI were $0.893,0.884$, and 0.881 , respectively. $\mathrm{Pa}$ rameters estimates were all significantly $(P<0.001)$ different from
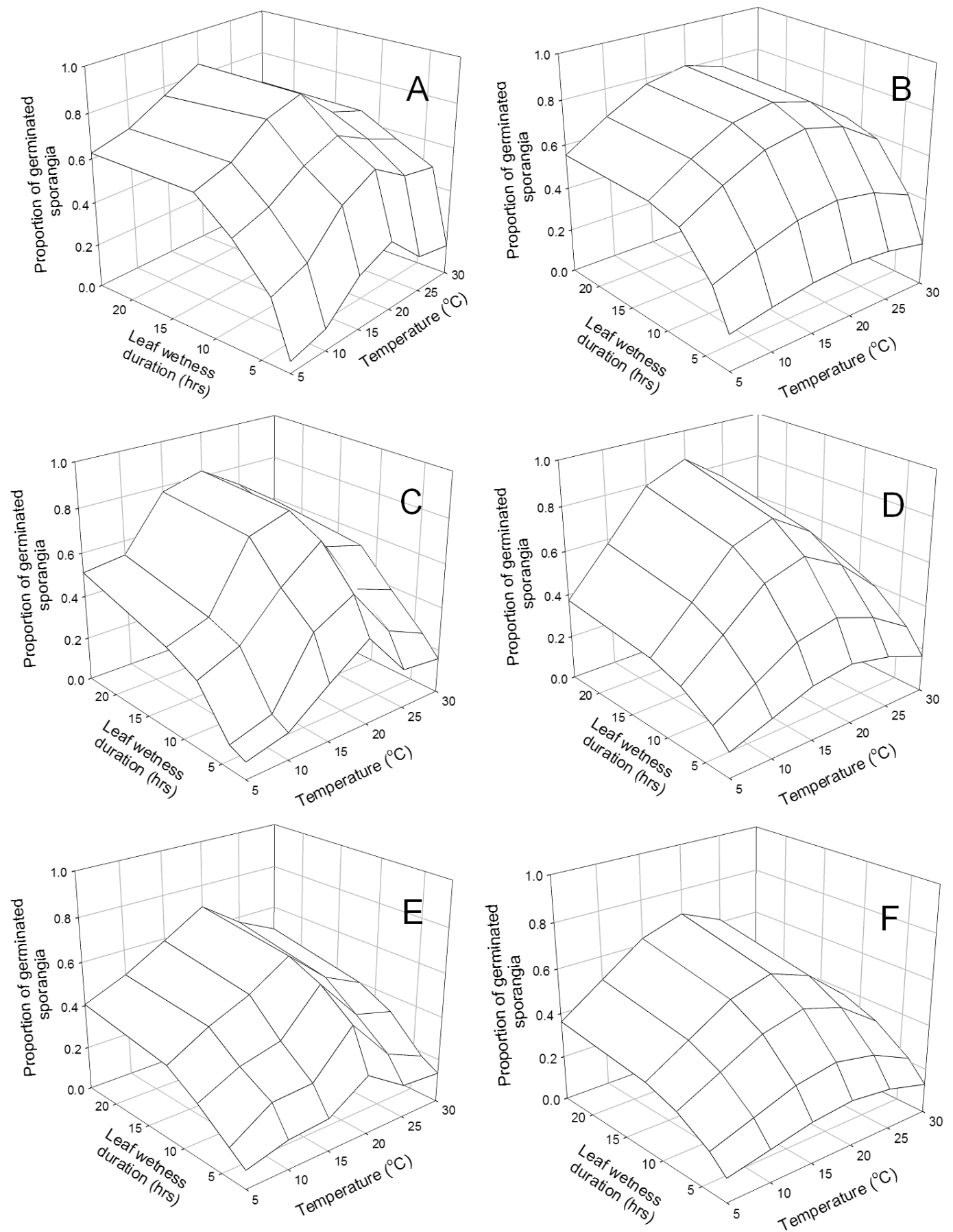

Fig. 1. Effects of temperature and leaf wetness duration on sporangia germination on leaves of three cucurbit host types inoculated with Pseudoperonospora cubensis Observed values are for A, cantaloupe ('Kermit'); C, cucumber ('Straight 8'); and E, acorn squash ('Table Queen'). Predicted values for B, cantaloupe; D, cucumber; and F, acorn squash are from fitting observed values to the model $\left.f(w, t)=f(t) \times\left(1-\exp \{-[B \times w]]^{D}\right\}\right)$. 
zero, except for the parameter $h$. The corresponding asymptotic standard errors (SEs) for germination (Table 3), disease severity at 5 and 7 DAI (Table 4) were not very large (SE < 4.0), except for the parameter $f$, where the SE was fairly large for germination (SE $=10.38$ ) on cantaloupe. For all host types, $G$ and $F$ were the mostand least-precisely estimated parameters, respectively.

Differences among host types were mainly characterized by differences in the parameter $E$, the upper limit of germination or disease severity. For germination, $E$ was highest for cucumber (90\%), intermediate for cantaloupe $(81 \%)$, and lowest for squash $(72 \%)$ (Table 3). For disease severity at 5 DAI, the parameter $E$ was highest for cucumber (32\%) and lowest for cantaloupe (19\%) (Table 4). Similarly, for disease severity at 7 DAI, parameter $E$ was highest for cucumber and squash and lowest for cantaloupe (Table 4). At the optimum temperatures, germination and disease severity values approached their upper limits for all host types (Fig. 4). Although the rate of change with respect to $t$ (parameter $F$ ) was the least-precisely estimated parameter, differences among host types in estimates of $F$ were fairly consistent for disease severity (Table 4).

Risk prediction charts. Based on disease severity evaluated at 7 DAI, the risk threshold model indicated that $10 \%$ leaf area infected in cantaloupe would occur when $t=6$ to $30^{\circ} \mathrm{C}$ and $w=2$ to $10 \mathrm{~h}$. The corresponding range for cucumber was $t=5$ to $30^{\circ} \mathrm{C}$ and $w=$ 1 to $5 \mathrm{~h}$, while that for squash was $t=5$ to $21^{\circ} \mathrm{C}$ and $w=1$ to 14 (Fig. 5). At any given temperature, the duration of leaf wetness required to cause disease was longer for cantaloupe than for cucumber (Fig. 5). For example, at $18^{\circ} \mathrm{C}, 20 \%$ disease severity was
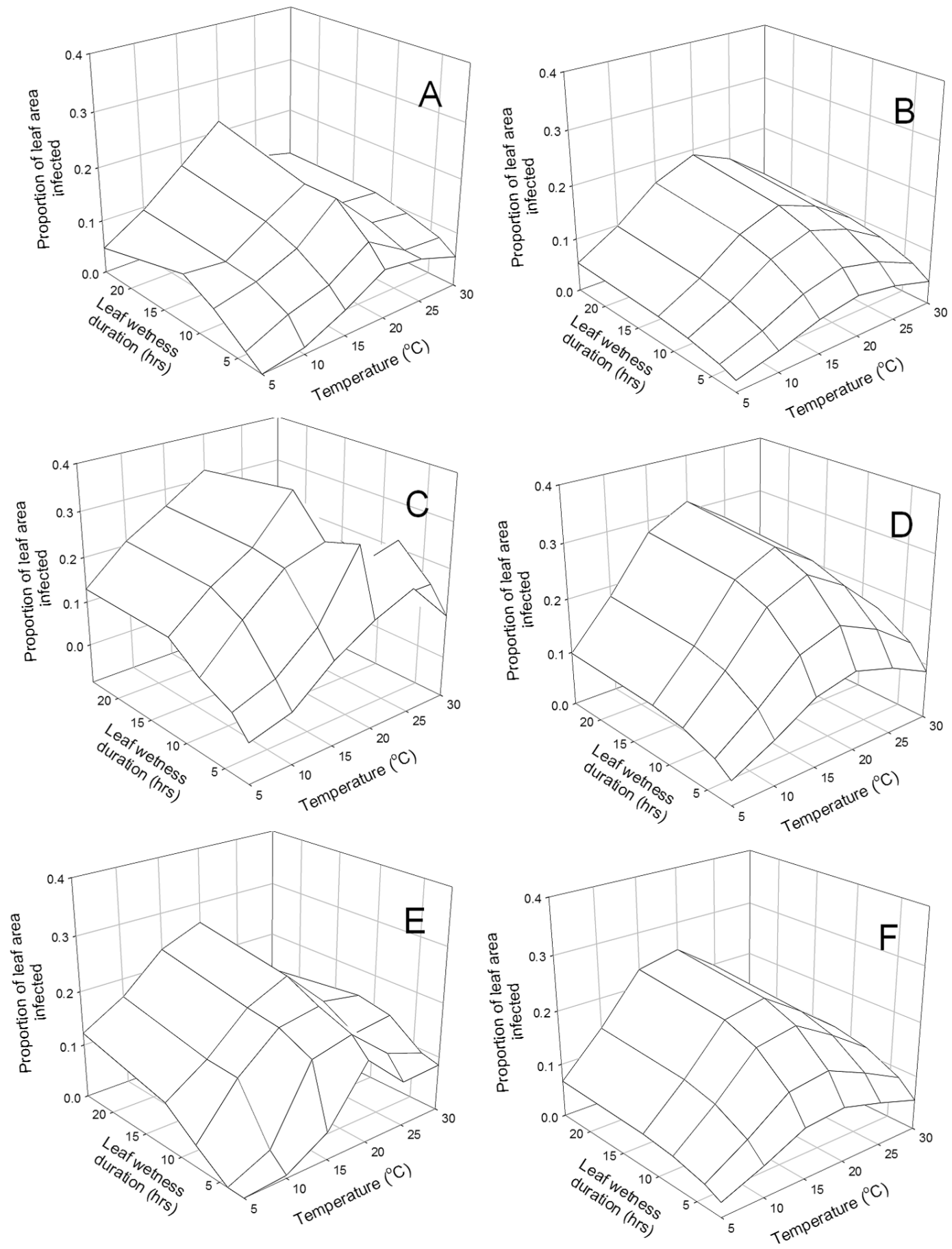

Fig. 2. Proportion of leaf area infected for three cucurbit host types 5 days after inoculation with Pseudoperonospora cubensis. Observed values are for $\mathbf{A}$, cantaloupe ('Kermit'); C, cucumber ('Straight 8'); and E, acorn squash ('Table Queen'). Predicted values for B, cantaloupe; D, cucumber; and F, acorn squash are from fitting observed values to the model $f(w, t)=f(t) \times(1-\exp \{-[B \times w]\})$. 
expected on cantaloupe after $8 \mathrm{~h}$ of leaf wetness compared with only $2 \mathrm{~h}$ for cucumber.

\section{Discussion}

In this study, we quantitatively defined the effects of temperature and duration of leaf wetness on sporangia germination and infection of three different cucurbit host types by $P$. cubensis in controlled conditions. Cucurbit host type, temperature, and duration of leaf wetness significantly affected sporangia germination and disease severity. Further, sporangia germination and infection were significantly affected by the interactions between host type and temperature and host type and leaf wetness duration. Differences between the host types were mainly characterized by differences in the upper limit of sporangia germination or infection and the rate of change in these two response variables with respect to temperature. Prediction charts were developed from response surface models and they could be used to estimate the risk of cucurbit downy mildew based on prevailing or forecasted temperature and leaf wetness duration.

Previous studies $(3,4,27)$ investigated independently the effects of temperature and leaf wetness on the infection parameters of $P$. cubensis. Recently, quantitative models were developed that define combined effects of temperature and leaf wetness duration on sporangia germination and infection by $P$. cubensis (1). Our results are generally in agreement with those reported in previous studies. For example, in the present study, the optimum temperature for infection was 17 to $21^{\circ} \mathrm{C}$, which is similar to the range of 15 to $20^{\circ} \mathrm{C}$ reported by Cohen (3). In the study by Arauz et al. (1), the opti-
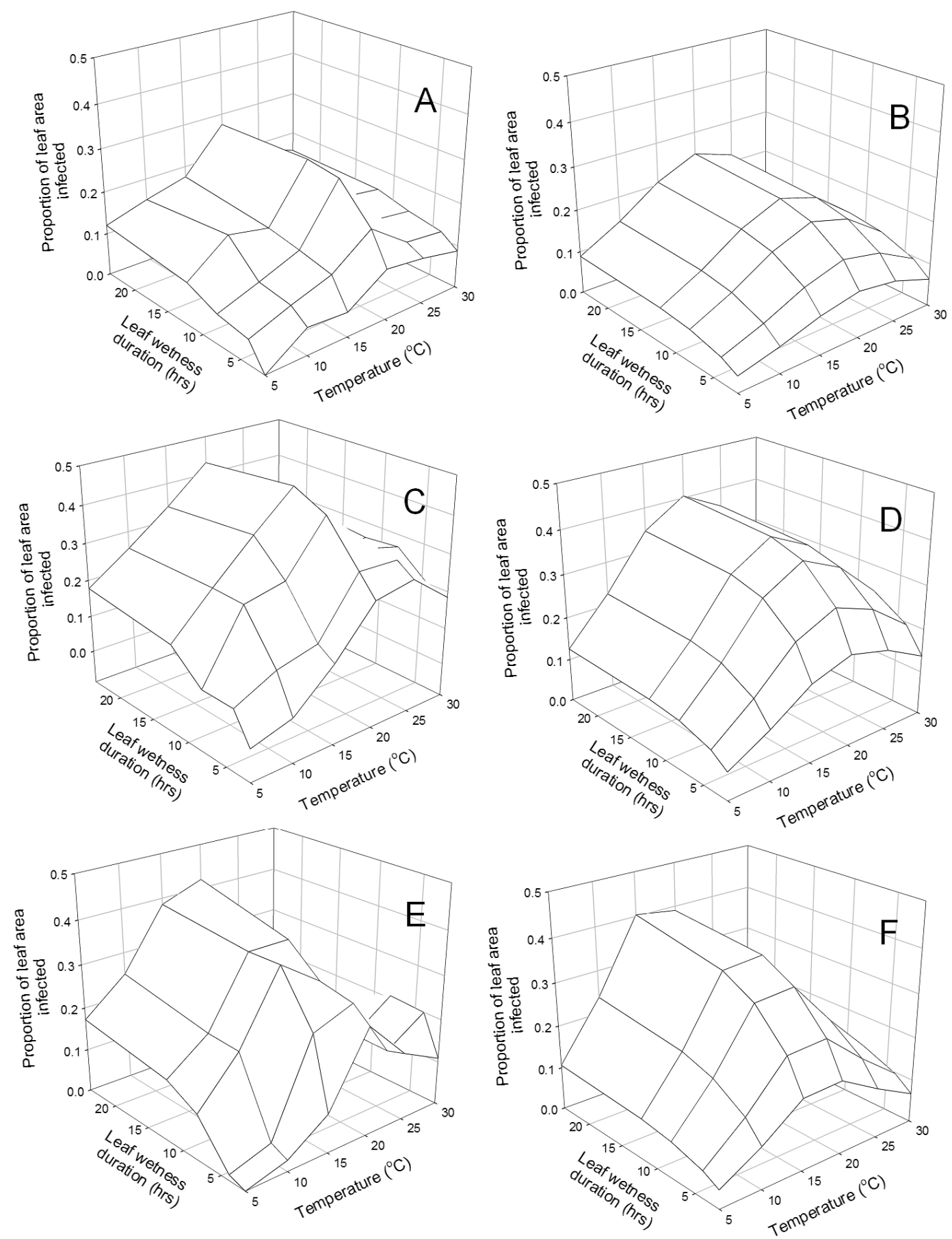

Fig. 3. Proportion of leaf area infected for three cucurbit host types 7 days after inoculation with Pseudoperonospora cubensis. Observed values are for $\mathbf{A}$, cantaloupe ('Kermit'); C, cucumber ('Straight 8'); and E, acorn squash ('Table Queen'). Predicted values for B, cantaloupe; D, cucumber; and F, acorn squash are from fitting observed values to the model $f(w, t)=f(t) \times(1-\exp \{-[B \times w]\})$. 
mum temperature for sporangia germination was 16 to $18^{\circ} \mathrm{C}$, which is similar to the range of 18 to $20^{\circ} \mathrm{C}$ reported in this study. However, our results are different from previous reports on the maximal temperature for infection. Previous studies $(3,4)$ reported $25^{\circ} \mathrm{C}$ as the maximal temperature for infection, with very minimal or no infection at $28^{\circ} \mathrm{C}$. However, we observed infection at $30^{\circ} \mathrm{C}$, a much higher temperature than previously reported. Our results on a high maximal temperature for infection are similar to those reported recently for $P$. cubensis (1). It has been suggested that a change in the population structure of $P$. cubensis that has been linked to the resurgence of the disease in 2004 in Europe and the United States may have generated new strains of the pathogen $(8,18)$. This change in the population structure of $P$. cubensis may have been due to the migration of virulent strains from Asia to Europe and the United States (17). Oospore formation and sexual reproduction in $P$. cubensis was reported for the first time under controlled conditions (5) and, although this process can also generate more virulent strains of the pathogen, its impact on the population biology of $P$. cubensis in the field is yet to be determined. Nonetheless, these new strains of P. cubensis are more aggressive and adapted to much higher maximal temperatures for infection. Adaptation to high temperatures by a new strain of a pathogen has also been reported for Puccinia striiformis f. sp. tritici causing stripe rust of wheat (10) in the United States.

In earlier work on the infection parameters of Pseudoperonospora cubensis, it was reported that the highest increase in infection occurred between 4 and 6 DAI (3) but the dynamics of this rapid increase in relation to temperature was not established. In this study, the range for the optimum temperature for infection became broader with increasing length of time between inoculation and disease assessment. The coalescing of individual lesions when lesions expand may explain this broadening of the optimum temperature. However, downy mildew lesions do not generally expand substantially after symptom appearance (16). Thus, it is highly possible that a distributed delay in lesion development may be responsible for the broadening of optimum temperature for infection from 5 to 7 DAI (16). This distributed delay in lesion development is probably more pronounced for infection that originated at the extremes than in the middle of the temperature range evaluated in this study. Given the similarity of the response surfaces and asymptotic parameters for germination and infection 7 DAI, the 7day data set probably depicts true terminal infection levels.

Advisory guidelines on the development of cucurbit downy mildew have been based on studies on the effects of temperature and leaf wetness duration involving a single cucurbit host type $(1,3,27)$. However, cucurbit host types differentially respond to the disease under field conditions (13). Thus, it is expected that advisory guidelines based on studies conducted on a single host may be less accurate across host types. Taking into consideration the differences among host types should, therefore, increase the predictive capacity of disease advisory systems. In the present study, combined effects of temperature and leaf wetness duration on development of cucurbit downy mildew were investigated using three cucurbit host types. Our results clearly show that the interaction of host type with temperature and wetness duration significantly influenced the magnitude and extent of either sporangia germination or infection. First, fewer hours of wetness were required to gain a specific level of germination or infection as temperature approached the optimum level. Second, at a given temperature, fewer hours of leaf wetness were required to result in a given level of disease severity on cucumber compared with squash or cantaloupe. The interaction of different host cultivars with temperature and leaf wetness on infection parameters of plant pathogens has been reported in other pathosystems. For example, Wu et al. (26) characterized cultivar responses to temperature and wetness duration for components of infection by Cercospora

Table 3. Parameter estimates for the model, $f(w, t)=f(t) \times\left(1-\exp \left\{-[B \times w]^{D}\right\}\right)$, characterizing the effects of temperature and wetness duration on germination of Pseudoperonospora cubensis sporangia on three cucurbit host types ${ }^{\mathrm{a}}$

\begin{tabular}{|c|c|c|c|c|c|c|c|c|c|}
\hline \multirow[b]{2}{*}{ Parameter } & \multicolumn{3}{|c|}{ Cantaloupe ('Kermit') } & \multicolumn{3}{|c|}{ Cucumber ('Straight 8') } & \multicolumn{3}{|c|}{ Acorn squash ('Table Queen') } \\
\hline & Estimate & $C I_{\mathrm{L}}$ & $C \boldsymbol{I}_{\mathrm{U}}$ & Estimate & $C I_{\mathrm{L}}$ & $C \boldsymbol{I}_{\mathrm{U}}$ & Estimate & $C I_{\mathrm{L}}$ & $C I_{\mathrm{U}}$ \\
\hline$B$ & 0.24 & 0.19 & 0.28 & 0.16 & 0.10 & 0.23 & 0.15 & 0.10 & 0.20 \\
\hline$D$ & 1.39 & 1.00 & 1.78 & 0.91 & 0.59 & 1.23 & 0.92 & 0.66 & 1.17 \\
\hline$E$ & 0.81 & 0.75 & 0.88 & 0.90 & 0.75 & 1.05 & 0.72 & 0.61 & 0.82 \\
\hline$F$ & 22.65 & 1.21 & 44.08 & 18.99 & 11.09 & 26.89 & 22.54 & 14.75 & 30.33 \\
\hline$G$ & 0.14 & 0.07 & 0.19 & 0.21 & 0.17 & 0.24 & 0.19 & 0.41 & 0.24 \\
\hline$H$ & 1.48 & -2.46 & 5.42 & 0.94 & -0.24 & 2.12 & 1.66 & -0.44 & 3.77 \\
\hline
\end{tabular}

${ }^{\text {a }}$ In the model, $\left.f(t)=E^{\prime}\{\exp [(t-F) G /(H+1)]\} /\{1+\exp (t-F) G]\right\}$, in which $E^{\prime}=E[(H+1) / H] H^{1 /(H+1)}$. The parameters $B, D, E, F, G$, and $H$ are as defined in the main text; $t=$ temperature and $w=$ leaf wetness duration; $C I_{\mathrm{L}}$ and $C I_{\mathrm{U}}=$ asymptotic lower and upper limits of the $95 \%$ confidence interval, respectively, around the parameter estimate.

Table 4. Parameter estimates for the model, $f(w, t)=f(t) \times\left(1-\exp \left\{-[B \times w]^{D}\right\}\right)$, characterizing the effects of temperature and wetness duration on infection of Pseudoperonospora cubensis sporangia on three cucurbit host types 5 and 7 days after inoculation (DAI) ${ }^{\mathrm{a}}$

\begin{tabular}{|c|c|c|c|c|c|c|c|c|c|}
\hline \multirow[b]{2}{*}{ DAI, parameter } & \multicolumn{3}{|c|}{ Cantaloupe ('Kermit') } & \multicolumn{3}{|c|}{ Cucumber ('Straight 8') } & \multicolumn{3}{|c|}{ Acorn squash ('Table Queen’) } \\
\hline & Estimate & $C I_{\mathrm{L}}$ & $C \boldsymbol{I}_{\mathrm{U}}$ & Estimate & $C I_{\mathrm{L}}$ & $C \boldsymbol{I}_{\mathrm{U}}$ & Estimate & $C I_{\mathrm{L}}$ & $C I_{\mathrm{U}}$ \\
\hline \multicolumn{10}{|l|}{5} \\
\hline$B$ & 0.19 & 0.06 & 0.33 & 0.27 & 0.13 & 0.42 & 0.23 & 0.09 & 0.35 \\
\hline$D$ & 0.78 & 0.34 & 1.21 & 0.84 & 0.30 & 1.39 & 0.86 & 0.34 & 1.37 \\
\hline$E$ & 0.19 & 0.15 & 0.25 & 0.32 & 0.26 & 0.38 & 0.26 & 0.20 & 0.31 \\
\hline$F$ & 19.13 & 12.50 & 25.77 & 17.25 & 8.94 & 25.56 & 15.34 & 9.13 & 21.56 \\
\hline$G$ & 0.24 & 0.20 & 0.29 & 0.23 & 0.18 & 0.29 & 0.26 & 0.19 & 0.34 \\
\hline$H$ & 0.81 & -0.18 & 1.80 & 0.61 & -0.30 & 1.51 & 0.45 & -0.13 & 1.04 \\
\hline \multicolumn{10}{|l|}{7} \\
\hline$B$ & 0.27 & 0.13 & 0.39 & 0.34 & 0.16 & 0.52 & 0.21 & 0.01 & 0.39 \\
\hline$D$ & 0.87 & 0.34 & 1.41 & 0.84 & 0.19 & 1.49 & 0.76 & 0.16 & 1.36 \\
\hline$E$ & 0.25 & 0.20 & 0.29 & 0.44 & 0.32 & 0.51 & 0.42 & 0.31 & 0.59 \\
\hline$F$ & 21.65 & 13.33 & 29.96 & 17.65 & 7.90 & 27.41 & 16.17 & 10.67 & 21.67 \\
\hline$G$ & 0.23 & 0.16 & 0.30 & 0.22 & 0.17 & 0.27 & 0.30 & 0.23 & 0.37 \\
\hline$H$ & 1.29 & -0.63 & 3.21 & 0.59 & -0.42 & 1.59 & 0.65 & -0.11 & 1.41 \\
\hline
\end{tabular}

${ }^{a}$ In the model, $\left.f(t)=E^{\prime}\{\exp [(t-F) G /(H+1)]\} /\{1+\exp (t-F) G]\right\}$, in which $E^{\prime}=E[(H+1) / H] H^{1 /(H+1)}$. The parameters $B, D, E, F, G$, and $H$ are as defined in the main text; $t=$ temperature and $w=$ leaf wetness duration; $C I_{\mathrm{L}}$ and $C I_{\mathrm{U}}=$ asymptotic lower and upper limits of the $95 \%$ confidence interval, respectively, around the parameter estimate. 
arachidicola and observed that a longer wetness period was required to achieve a specific level of disease for a partially resistant compared with a susceptible cultivar. When all other factors that contribute to disease are held constant, cucumber is more susceptible to downy mildew than other cucurbitaceous host types $(13,23)$. Thus, the fewer hours of leaf wetness required to result in a given level of disease severity on cucumber compared with squash is most likely due to differences in host susceptibility to $P$. cubensis.

A modified version of a Weibull equation previously developed and validated to describe the response of the infection parameters of $P$. cubensis to combined effects of temperature and leaf wetness (1) was used to model the effects on temperature and wetness duration on germination and infection for three cucurbit host types. This model resulted in a good description of our data as indicated by the relatively small asymptotic SEs and high correlation coefficients between observed and predicted data. Further, there was a clear relationship between the asymptote and temperature for each host type. Differences among the host types were primarily characterized by the upper limit of germination or infection (parameter $E$ ). For both germination and infection, the parameter $E$ was consistently larger for cucumber than either cantaloupe or squash. Differences in the upper limit of disease $(11,15)$ or intrinsic rate of disease increase $(19,25)$ have been used to characterize host resistance. In this study, host type had a large effect on parameter $E$ but had no effect on the optimum temperature. Further, unlike parameter $E$, intrinsic rate parameters (parameters $B$ or $F$ ) were more variable across host types when disease severity was assessed at 5 and 7 DAI. Thus, our results tend to support variation in the upper limit
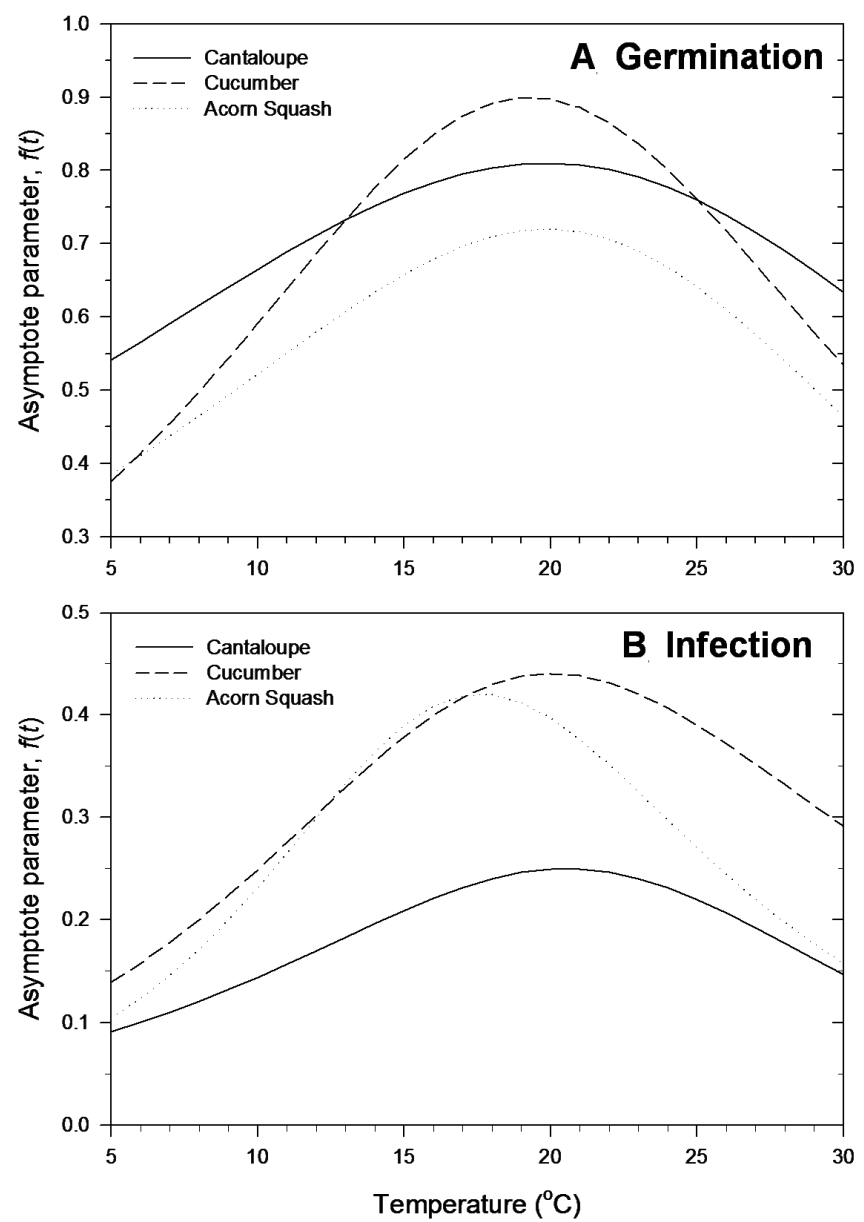

Fig. 4. Relationship between the asymptote, $f(t)$, and temperature based on model estimates for predicting sporangia germination and proportion of leaf area infected 7 days after inoculation of cucurbit host types with Pseudoperonospora cubensis. The cultivars used for cantaloupe, cucumber, and acorn squash were 'Kermit', 'Straight 8', and 'Table Queen', respectively. as the operating mechanism for cucurbit downy mildew. Nonetheless, cucurbit hosts are exposed to multiple cycles of disease in the field as opposed to a single cycle of infection used in this study. It is likely that a combination of other components of disease resistance determine the extent in the reduction of the disease on squash or cantaloupe versus cucumber over multiple infection cycles under field conditions.

A major goal of this study was to generate information that could be used to improve the cucurbit downy mildew forecasting system (12). This advisory system issues a risk of initial infection based on the assumption that cucurbit host types respond similarly to infection by P. cubensis. The first spray is recommended if the
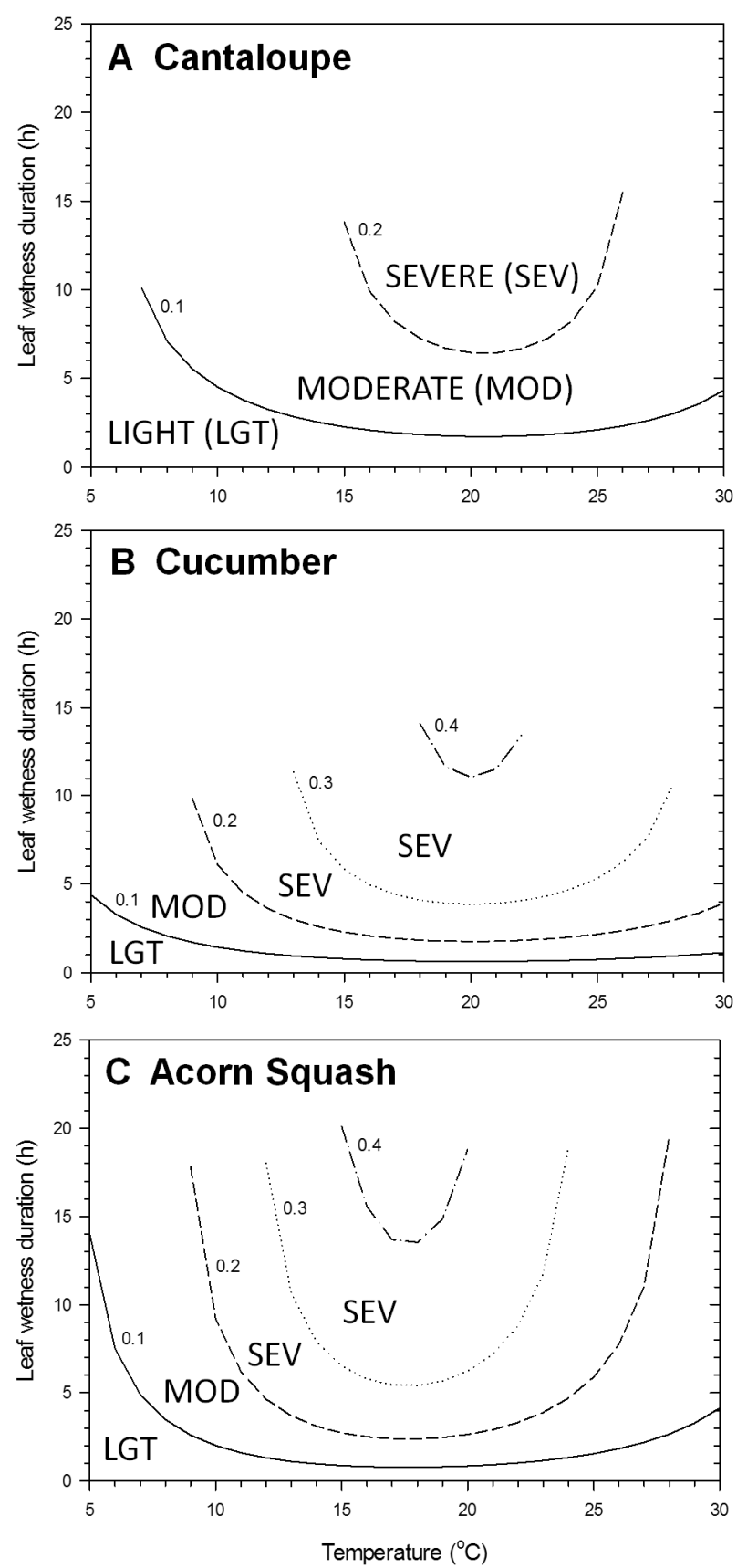

Fig. 5. Charts for risk prediction for cucurbit downy mildew infection of three cucurbit host types. A, cantaloupe ('Kermit'); B, cucumber ('Straight 8'); and C, acorn squash ('Table Queen'). Risk categories are based on the response surface models and isopaths separating the categories correspond to LGT = light (disease severity $=0.00$ to 0.10 ); $\mathrm{MOD}=$ moderate (disease severity $=0.11$ to 0.20 ), and $\mathrm{SEV}=$ severe (disease severity $>0.20$ ). Isopaths are based on predicted response surfaces for leaf area infected 7 days after inoculating plants with Pseudoperonospora cubensis. 
risk of infection is moderate to high. In this study, we developed host-based prediction charts that may have application in predicting the potential risk for disease development. Assuming that sporangia are available, these charts can be used in conjunction with the FLEXPART plume dispersal model (21) present in the forecasting system to identify locations of high risk for disease development based on forecasted temperature and duration of leaf wetness along projected trajectories of sporangia transport. For example, it is predicted that a severe risk of the disease will be observed for the squash when the temperature is $20^{\circ} \mathrm{C}$ and the duration of leaf wetness is $5 \mathrm{~h}$. Under the same environmental conditions, the predicted risk of disease development on cantaloupe and cucumber will be moderate and severe, respectively. Given this scenario, application of the initial fungicide spray would only be recommended for cucumber and squash fields but not cantaloupe fields. Clearly, the inclusion of host-based models describing the combined effects of temperature and leaf wetness on infection by $P$. cubensis will greatly improve the predictive capacity of the cucurbit downy mildew advisory system. Applying fungicides with single modes of action only if and when it is necessary can also slow the development of resistance in P. cubensis (20).

Under favorable conditions, downy mildew can spread rapidly and cucurbit growers are more concerned with whether infection will occur than in the actual level of infection. Thus, the timing of the initial fungicide spray is crucial in the management of the disease. It is important to note that, presently, no advisory system is available to determine the risk of the disease development during the growing season. Such a system is useful to guide within-season fungicide application after initial infection and should improve fungicide efficiency compared with the current calendar-based application schedule. Models developed in this study can be extended to incorporate the effects of host growth, fungicides, and interrupted leaf wetness to predict risk of disease development during the season. Thus, additional studies are needed to establish the impact of interrupted leaf wetness on the infection parameters of $P$. cubensis and the risk of disease development during the season. Further, although the Weibull model used to characterize the effects of cucurbit host types on infection parameters of $P$. cubensis has previously been validated (1), the infection risks presented in this study will need to be verified under field conditions prior to implementation in commercial cucurbit production. Variation in some of the results present in this study can be expected when using different cucurbit host types or if the susceptibility of a given host type changes due to changes in population of the pathogen.

\section{Literature Cited}

1. Arauz, L. F., Neufeld, K. N., Lloyd, A. L., and Ojiambo, P. S. 2010. Quantitative models for germination and infection of Pseudoperonospora cubensis in response to temperature and duration of leaf wetness. Phytopathology 100:959-967.

2. Arauz, L. F., and Sutton, T. B. 1989. Temperature and wetness duration requirements for apple infection by Botryosphaeria obtusa. Phytopathology 79:440-444.

3. Cohen, Y. 1977. The combined effects of temperature, leaf wetness, and inoculum concentration on infection of cucumbers with Pseudoperonospora cubensis. Can. J. Bot. 55:1478-1487.

4. Cohen, Y., and Rotem, J. 1969. The effects of lesion development, air temperature, and duration of moist period on sporulation of Pseudoperonospora cubensis in cucumbers. Israel J. Bot. 18:135-140.

5. Cohen, Y., Rubin, A. E., and Galperin, M. 2011. Formation and infectivity of oospores of Pseudoperonospora cubensis, the causal agent of downy mil- dew in cucurbits. Plant Dis. 95:874.

6. Hoagland, D. R., and Arnon, D. I. 1950. The water culture method for growing plants without soil. Calif. Agric. Exp. Stn. Circ. 347:1-23.

7. Lebeda, A. 1986. Pseudoperonospora cubensis. Pages 81-85 in: Methods of Testing Vegetable Crops for Resistance to Plant Pathogens. A. Lebeda, ed. Sempra Research Institute of Vegetable Crops, Czech Republic.

8. Lebeda, A., and Cohen, Y. 2011. Cucurbit downy mildew (Pseudoperonospora cubensis) — biology, ecology, epidemiology, host-pathogen interaction and control. Eur. J. Plant Pathol. 129:157-192.

9. Lebeda, A., and Widrlechner, M. P. 2003. A set of cucurbitaceae taxa for differentiation of Pseudoperonospora cubensis pathotypes. J. Plant Dis. Prot. 110:337-349.

10. Milus, E. A., Kristensen, K., and Hovmøller, M. S. 2009. Evidence for increased aggressiveness in a recent widespread strain of Puccinia striiformis f. sp. tritici causing stripe rust of wheat. Phytopathology 99:89-94.

11. Neher, D. A., and Campbell, C. L. 1992. Underestimation of disease progress rates with the logistic, monomolecular, and Gompertz models when maximum disease intensity is less than 100 percent. Phytopathology 82:811-814.

12. Ojiambo, P. S., Holmes, G. J., Britton, W., Keever, T., Adams, M. L., Babadoost, M., Bost, S. C., Boyles, R., Brooks, M., Damicone, J., Draper, M. A., Egel, D. S., Everts, K. L., Ferrin, D. M., Gevens, A. J., Gugino, B. K., Hausbeck, M. K., Ingram, D. M., Isakeit, T., Keinath, A. P., Koike, S. T., Langston, D., McGrath, M. T., Miller, S. A., Mulrooney, R., Rideout, S., Roddy, E., Seebold, K.W., Sikora, E. J., Thornton, A., Wick, R. L., Wyenandt, C. A., and Zhang, S. 2011. Cucurbit downy mildew ipmPIPE: a next generation web-based interactive tool for disease management and extension outreach. Plant Health Progress. Online publication. doi:10.1094/PHP2011- 0411-01-RV.

13. Ojiambo, P. S., Paul, P. A., and Holmes, G. J. 2010. A quantitative review of fungicide efficacy for managing downy mildew in cucurbits. Phytopathology 100:1066-1076.

14. Palti, J., and Cohen, Y. 1980. Downy mildew of cucurbits: the fungus and its hosts, distribution, epidemiology and control. Phytoparasitica 8:109-147.

15. Park, E. W., and Lim, S. M. 1985. Empirical estimation of the asymptotes of disease progress curves and the use of the Richards generalized rate parameters for describing disease progress. Phytopathology 75:786-791.

16. Populer, C. 1981. Epidemiology of downy mildews. Pages 57-105 in: The Downy Mildews D. M. Spencer, ed. Academic Press, New York.

17. Runge, F., Choi, Y. -J., and Thines, M. 2011. Phylogenetic investigations in the genus Pseudoperonospora reveal overlooked species and cryptic diversity in the P. cubensis species cluster. Eur. J. Plant Pathol. 129:135-146.

18. Savory, E. A., Granke, L. L., Quesada-Ocampo, L. M., Varbanova, M., Hausbeck, M. K., and Day, B. 2011. The cucurbit downy mildew pathogen Pseudoperonospora cubensis. Mol. Plant Pathol. 12:217-226.

19. Shaner, G., and Finney, R. E. 1977. The effect of nitrogen fertilization on the expression of slow-mildewing resistance in Knox wheat. Phytopathology 67:1051-1056.

20. Skylakakis, G. 1981. Effects of alternating and mixing pesticides on the buildup of fungal resistance. Phytopathology 71:1119-1121.

21. Stohl, A., Forster, C., Frank, A., Seibert, P., and Wotawa, G. 2005. Technical note: the Lagrangian particle dispersion model FLEXPART version 6.2. Atmos. Chem. Phys. Discuss. 5:4739-4799.

22. Thomas, C. E. 1996. Downy mildew. Pages 25-27 in: Compendium of Cucurbit Diseases. T. A. Zitter, D. L. Hopkins, and C. E. Thomas, eds. American Phytopathological Society, St. Paul, MN.

23. Urban, J., and Lebeda, A. 2006. Fungicide resistance in cucurbit downy mildew - methodological, biological and population aspects. Ann. Appl. Biol. 149:63-75.

24. Weibull, W. 1951. A statistical distribution of wide applicability. J. Appl. Mech. 18:293-297.

25. Wilcoxson, R. D., Skovmand, B., and Atif, A. H. 1975. Evaluation of wheat cultivars for ability to retard development of stem rust. Ann. Appl. Biol. 80:275-281.

26. Wu, L., Damicone, J. P., Duthie, J. A., and Melouk, H. A. 1999. Effects of temperature and wetness duration on infection of peanut cultivars by Cercospora arachidicola. Phytopathology 89:653-659.

27. Yang, X., Li, M., Zhang, Z., and Hou, Y. 2007. Early warning model for cucumber downy mildew in unheated greenhouses. N.Z. J. Agric. Res. 50:1261-1268. 